\title{
Sporadic Progressive Symmetric Erythrokeratoderma: Classical Presentation of a Rare Condition
}

\author{
Agarwal K'1, Agrawal S', Pradhan A ${ }^{2}$
}

${ }^{1}$ Department of Dermatology, Venereology and Leprology, ${ }^{2}$ Department of Pathology, B. P. Koirala Institute of Health Sciences, Dharan

\begin{abstract}
Progressive symmetrical erythrokeratodermia (PSEK) is a rare autosomal dominant genodermatosis presenting in infancy or early childhood. An 11-year-old male presented with a history of pruritic, erythematous, scaly, hyperkeratotic plaques first noted at 5 years of age, with no history of similar lesions in the family. Cutaneous examination revealed multiple, irregularly shaped, erythematous plaques with fine, shiny white, adherent scaling distributed symmetrically over the face, trunk, inguinal area, bilateral axillae and extensor surfaces of limbs. Palmoplantar keratoderma was present with thickened, yellowish discolored nails. No systemic abnormality was found. The histopathological findings were consistent with PSEK. The case is being reported to increase the awareness about this rare disease.

Key words: Genetic Heterogeneity; Keratoderma, palmoplantar; Nepal; Retinoids
\end{abstract}

\section{Introduction}

Erythrokeratoderma refers to a group of disorders

with both clinical and genetic heterogeneity that is characterized by well demarcated erythematous and hyperkeratotic plaques. Erythrokeratoderma is not a distinct clinicopathologic entity; rather, it is a descriptive term analogous to eczema and encompasses a range of diseases. ${ }^{1}$ Currently, erythrokeratodermas are divided into two major subtypes: Erythrokeratodermavariabilis and progressive symmetric erythrokeratoderma.

Progressive symmetric erythrokeratoderma (PSEK), or Gottron's syndrome, was first described by Darier in 1911, although it is named after Gottron's article in 1922. ${ }^{2}$ PSEK is predominantly inherited as an autosomal dominant trait with incomplete penetrance and variable expressivity, but there are reports that $40 \%$ of the cases occur sporadically. ${ }^{3}$

Inthe literature review, no published report of the disease in Nepal could be found. This case was an example of sporadic presentation. Despite classical clinical features, it can easily be misdiagnosed due to its rarity.

\section{Address of Correspondence}

Dr. Kompal Agarwal,

Junior Resident

Department of Dermatology, Venereology and Leprology

B. P. Koirala Institute of Health Sciences, Dharan

E-mail:dr.k.agarwal.92@gmail.com

\section{Case Report}

An 11-year-old Nepalese male presented to Dermatology OPDwith a history of pruritic, erythematous, scaly patches and hyperkeratotic plaques first noted at 5 years of age. He also had thickened soles and palms with hyperpigmentation and thickening over bilateral dorsal feet. These lesions followed a relapsing remitting pattern with a clear history of aggravation in the winter months and partial resolution in the summer. There was no family history of similar lesions.

He had been treated multiple times previously for eczema and fungal infection with only a mild improvement. The patient gave a history of complete

Submitted: $10^{\text {th }}$ December 2018

Accepted: $15^{\text {th }}$ February 2019

Published: $31^{\text {st }}$ March 2019

How to cite this article

Agarwal K, Agrawal S, Pradhan A. Sporadic Progressive Symmetric Erythrokeratoderma: Classical presentation of a rare Condition. Nepal Journal of Dermatology, Venereology and Leprology. 2019;17(1):69-72. doi: http://dx.doi. org/10.3126/ njdvl.v17i1.23293

\section{(c) (i)}

Licensed under CC BY 4.0 International License which permits use, distribution and reproduction in any medium, provided the original work is properly cited. 
resolution only two times in the last 7 years, each episode lasting for about 1-2 months.

Cutaneous examination revealed multiple, discrete to confluent, irregularly shaped, erythematous plaques with fine, shiny white, adherent scaling distributed symmetrically over the face, upper back, chest, inguinal area, bilateral axillae and extensor surfaces of upper and lower limbs (Fig 1 (a), (b), (c)), with involvement of dorsum of bilateral feet. Palmoplantar keratoderma was present (Fig 2). The nails of the bilateral feet were thickened with a yellowish discoloration, accompanied with transverse ridging in some of the nail plates (Fig 1 (d)). Scalp, hair, teeth and mucosa were normal. No systemic abnormality was detected.
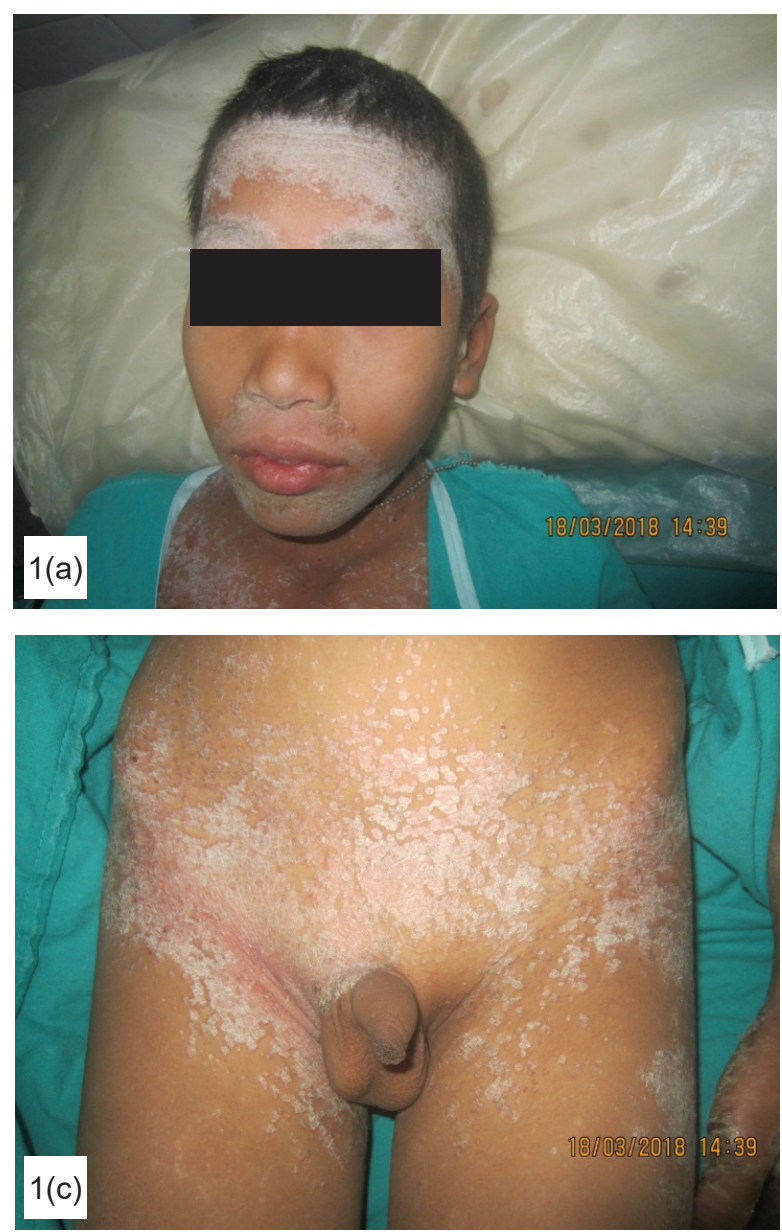

Figure 1a: Pretreatment: Face Figure 1c: Pretreatment: Abdomen
Histological examination of skin biopsy taken from the back showed basket weave hyperkeratosis with focal parakeratosis, mild papillomatosis, irregular psoriasiform hyperplasia and mild spongiosis. Keratinocytes showed vacuolization, predominantly in the granular layer. Papillary dermis showed proliferation of dilated and congested blood vessels with perivascular lymphocytic infiltration. No findings suggestive of Psoriasis or Pityriasis rubra pilaris were seen (Fig 3).

Based on the clinical and histopathological findings, a diagnosis of PSEK was made and the patient was started on topical steroids, keratolytics and emollients, with moderate improvement at 3-week follow-up. Fig 4 (a), (b), (c).
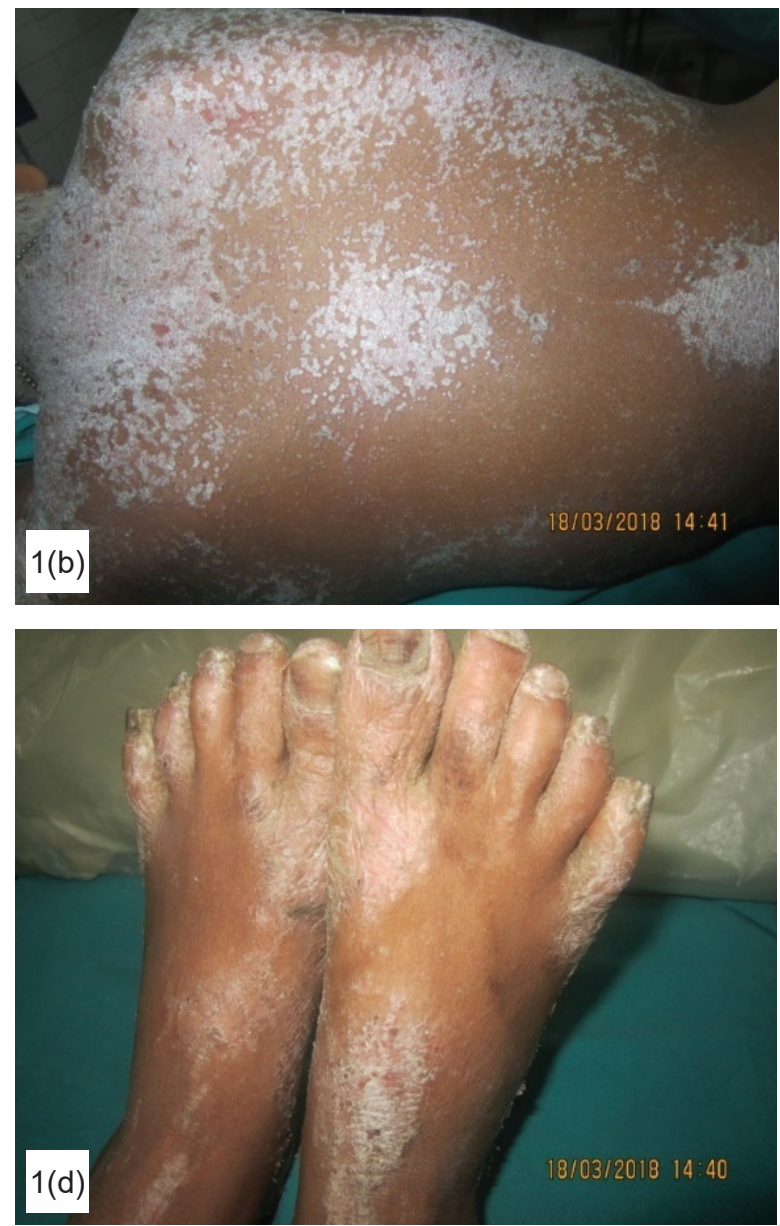

Figure 1b: Pretreatment: Back

Figure 1d: Pretreatment: Feet 


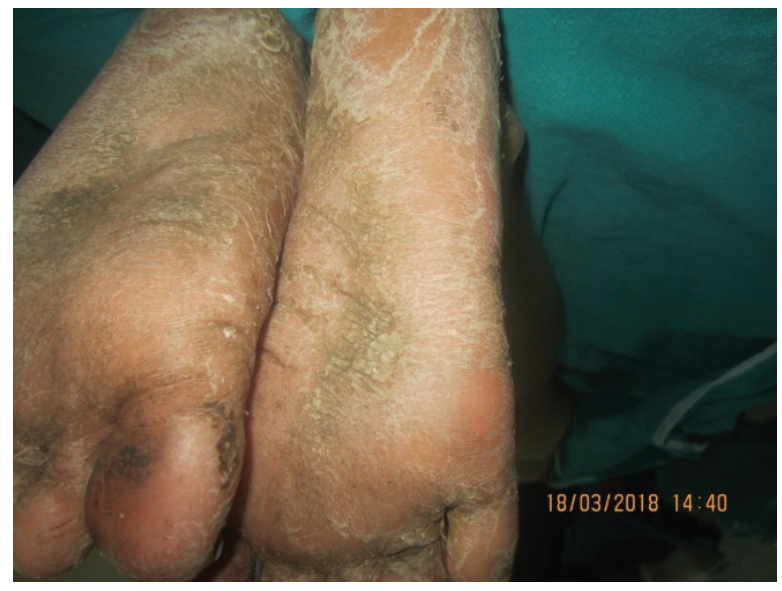

Figure 2: Palmo Plantar Keratoderma
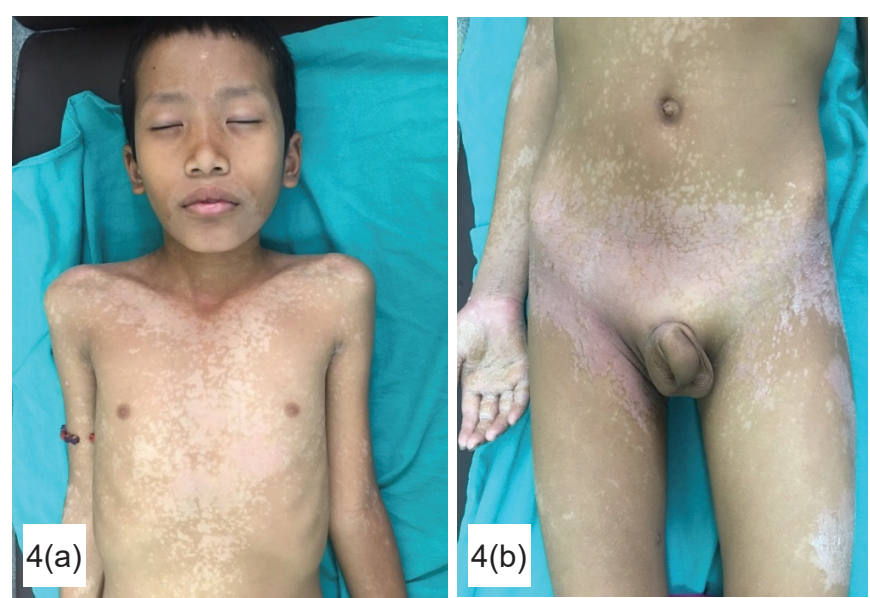

Figure 4 (a), (b), (c): 3 weeks follow up

\section{Discussion}

The prevalence of progressive symmetric erythrokeratoderma in the general population is unknown. The disorder was first described by Darier in 1911. Since then, fewer than 100 cases have been described in the medical literature. ${ }^{4}$

PSEK is typically caused by a genetic mutation in an as of yet unidentified gene(s), which may occur sporadically or be inherited as an autosomal dominant trait. The genetic analysis in PSEK patients has shown mutation in the loricrin protein with the gene coding region located on chromosome $1 q 21.3 .{ }^{5}$ Recently, a mutation in GJB4, which encodes connexion 30.3, was found in patients from Netherlands with either PSEK or EKV. ${ }^{6}$

PSEK is clinically differentiated from erythrokeratodermavariabilis (EKV), its closest differential diagnosis, by well demarcated nonmigratory erythematous plaques in contrast to the migratory plaques seen in the latter and in a greater

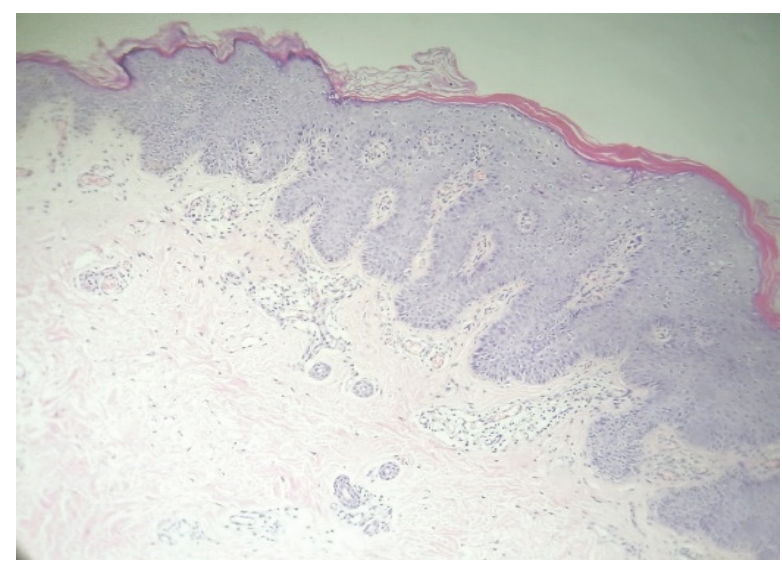

Figure 3: Histopathology of plaque on back, $H$ \& $E$ Stain, $4 \mathrm{X}$

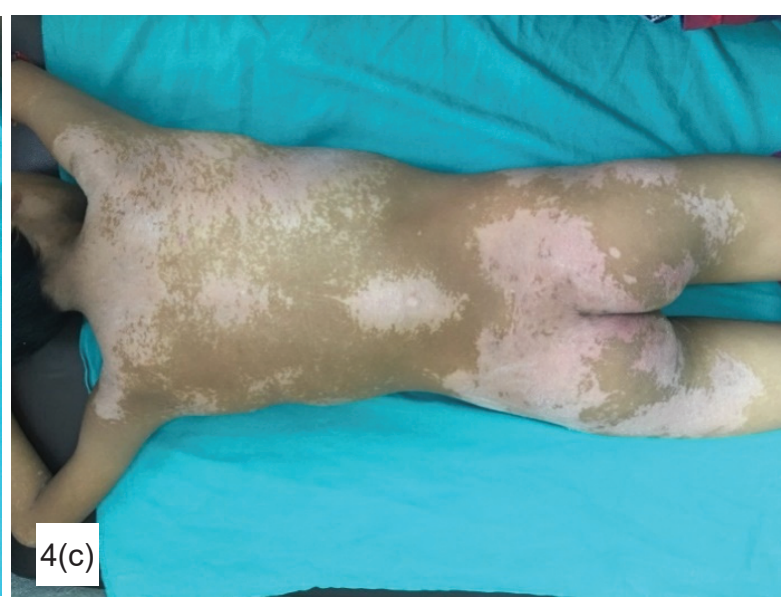

incidence of palmoplantar keratoderma. Also, as the name would suggest, the symmetry of the lesions in PSEK is more striking than in EKV. Psoriasis and Pityriasis rubra pilaris can be ruled out on histopathology.

The treatment options for PSEK include topical keratolytics, emollients, steroids, retinoids and oral retinoids. Use of topical calcipotriol with the good response has been reported in a patient. ${ }^{7}$

\section{Conclusion}

PSEK is a rare genodermatosis usually presenting in infancy or early childhood. The case is being reported to increase the awareness about thisrare disease. As the histopathology is generally non-specific, the diagnosis depends mostly on clinical findings, but may be missed due to unfamiliarity. An early diagnosis may help in proper investigation and management and prevent unnecessary treatment.

Financial disclosure: None.

Conflict of interest to disclosure: None declared. 


\section{References}

1. Rogers M. Erythrokeratodermas: a classification in a state of flux? Australas J Dermatol. 2005;46:127-41.https://doi.org/10.1111/j.14400960.2005.00165.x

2. Gottron HA. Congenital symmetrical progressive erythrokeratoderma. Arch Dermatol Syph.1923;7:416.

3. Khoo BP, Tay YK, Tan SH. Generalized erythematous plaques. Progressive symmetric erythrokeratoderma (PSEK) (erythrokeratodermia progressive symmetrica). Arch Dermatol 2000;136:665-8. https://doi.org/10.1001/ archderm.136.5.665

4. Richard G. Progressive Symmetric Erythrokeratodermia. NORD Guide to Rare Disorders. Lippincott Williams \& Wilkins. Philadelphia, PA. 2003.p.111-2.
5. Suga $Y$, Jarnik $M$, Attar PS, Longley MA, Bundman $D$, Steven AC, et al. Transgenic mice expressing a mutant form of loricrin reveal the molecular basis of the skin diseases, Vohwinkel syndrome and progressive symmetric erythrokeratoderma. J Cell Biol. 2000;151:401-12. https://doi.org/10.1083/ jcb.151.2.401

6. van Steensel MA, Oranje $A P$, van der Schroeff JG, Wagner A, van Geel M, et al. The missense mutation G12D in connexion 30.3 can cause both erythrokeratodermiavariabilis of Mendes da Costa and progressive symmetric erythrokeratodermia of Gottron. Am J Med Genet A. 2009;149:657-61. https://doi.org/10.1002/ajmg.a.32744

7. Bilgin L, Bozdag KE, Uysal S, Ermete $M$. Progressive symmetrical erythrokeratoderma - Response to topical calcipotriol. J Dermatol Case Rep. 2011;3:50-2. https://doi.org/10.3315/ jdcr.2011.1075 